\author{
ارزيابى مرفومترى، مدلسازى و استخراج آبراههها از مدل رقومى ارتفاع \\ با استفاده از مدل زير بيكسل جاذبه (DEM) \\ مرضيه مكرم'، عبدالرسول زارعى ' و محمد جواد اميرى

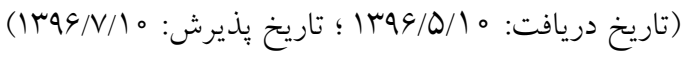

جكيده

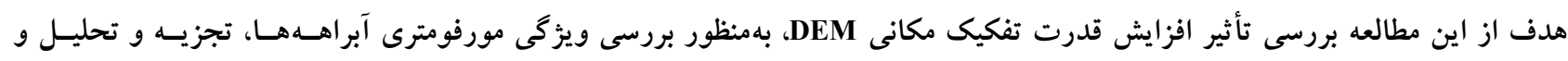

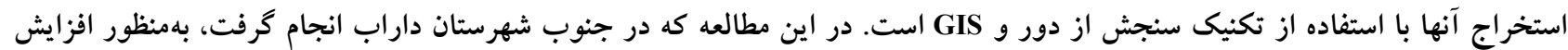

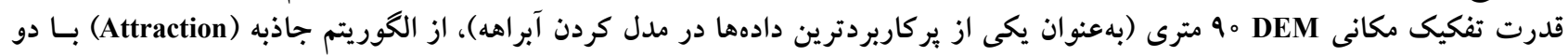

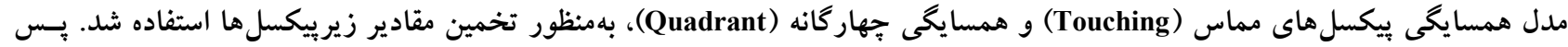

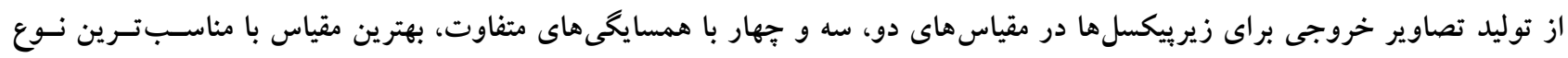

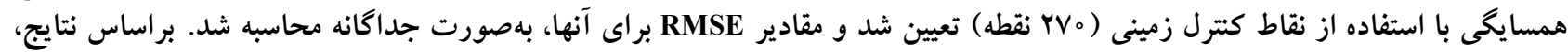

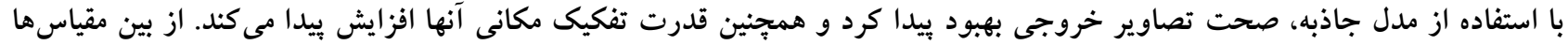

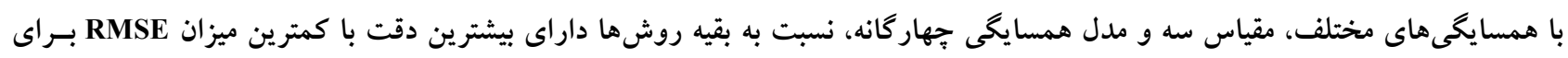

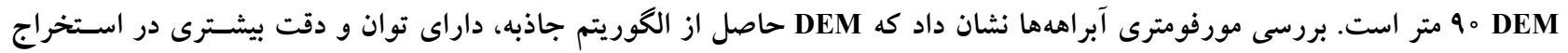

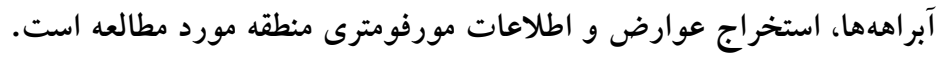

وازههاى كليدى: مورفومترى آبراهه، مدلسازى آبراهه، GIS، الخوريتم جاذبه، زيرييكسل، DEM

ا. بخش مرتع و آبخيزدارى، دانشكده كشاورزى و منابع طبيعى داراب، دانشگاه شيراز، شيراز

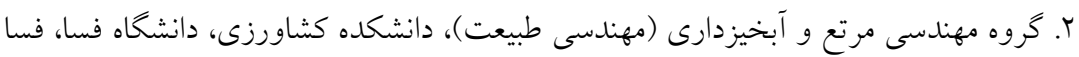

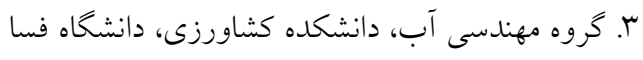

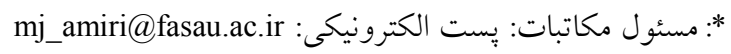




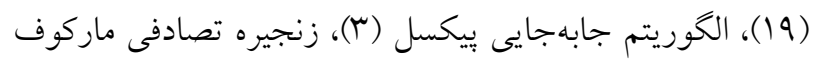

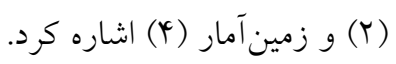

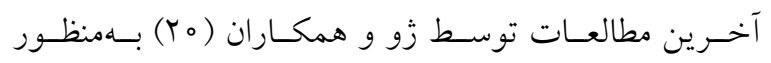

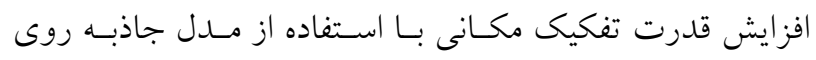
تصاوير ماهوارهاى انجام شد. نتايج نشان داد كه استفاده از ايسن مدل بهمنظور افزايش قدرت تفكيك بسيار مفيد اسـت. در مــدل

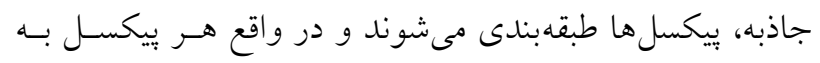

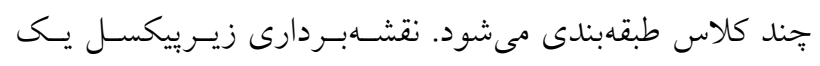

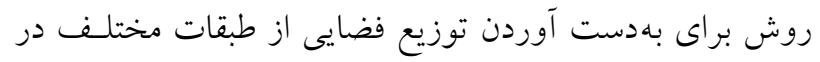

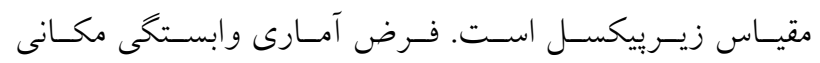

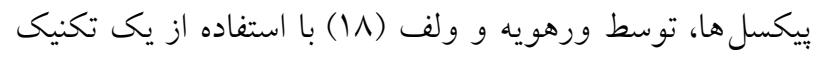

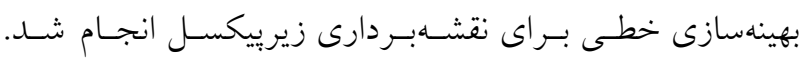

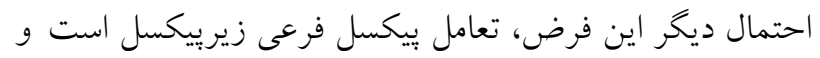
توسط مرتنس و همكاران (0) ارائه شد. مـرتنس و همكــاران،

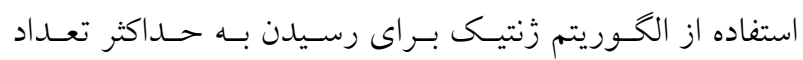

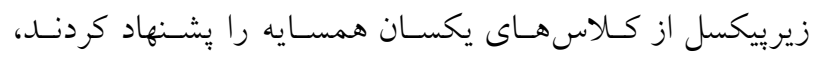

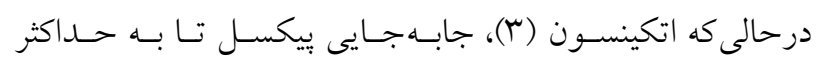
رساندن همبستخى مكانى بين زيرييكسل همسايه را ارائسه كرد.

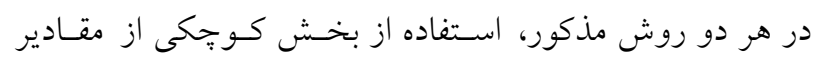

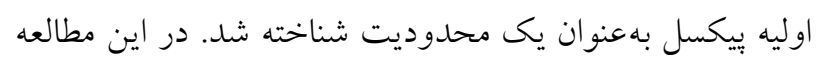

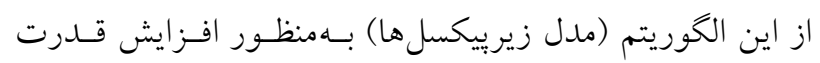
تفكيك مكانى DEM ه9 مترى بهعنوان يكسى از بركساربردترين

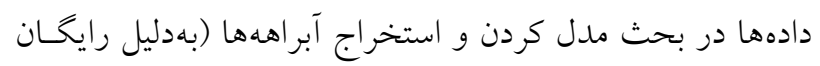

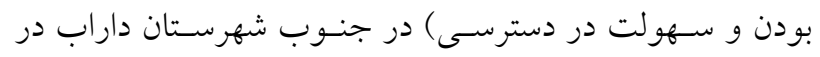

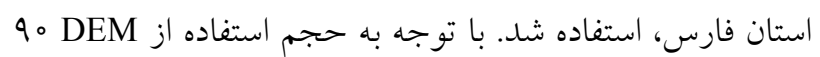

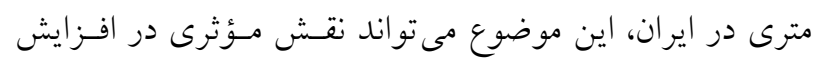

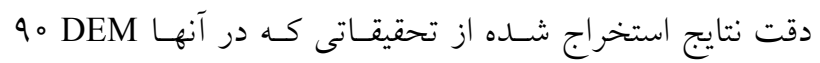
مترى مورد استفاده قرار كرفته است، داشته باشد.

\section{مواد و روشها}

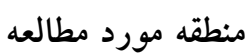

منطقه مورد مطالعه در ها ا كيلومترى شهرستان داراب (قلاتويه)
امروزه از روش هاى كمى بهمنظور بررسى آبراهـهــا استفاده مىشود (9). در اين روشها، بررسى مورفومترى حوضه آبخيز

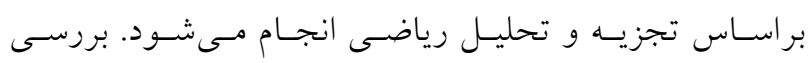

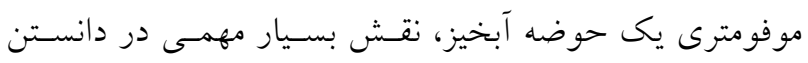

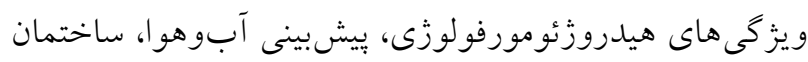

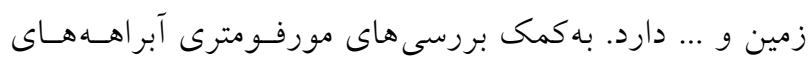

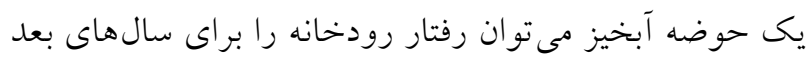

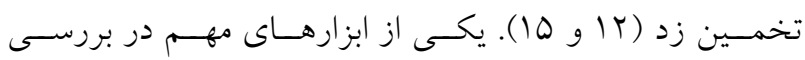

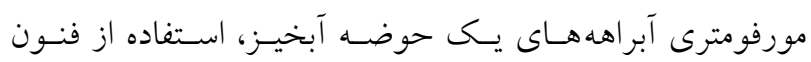

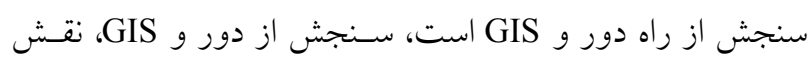

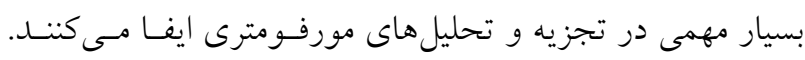

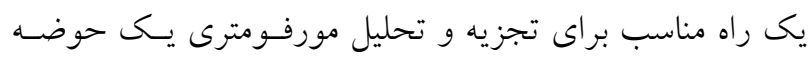

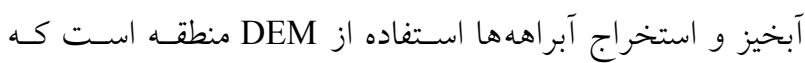
منجر به تسريع و دقت بيشتر محاسبات مىشود (N).

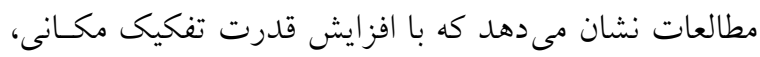

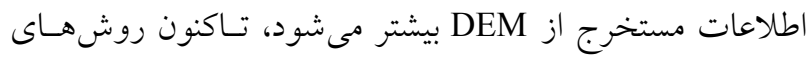
مختلفسى بــمنظــور افـزايش قــدرت تفكيـى مكـانى تصـاوير ماهوارهاى مورد استفاده قرار خرفته است ولى هيجِكـدام از ايـنـ روشها روى مدلهاى رقومى ارتفاعى (DEM) اعمال نشدهاند.

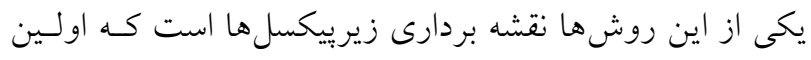

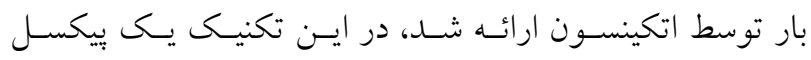

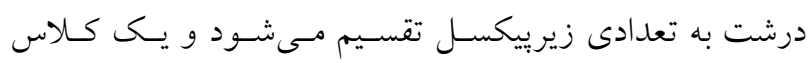

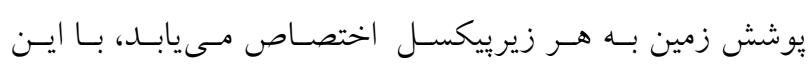

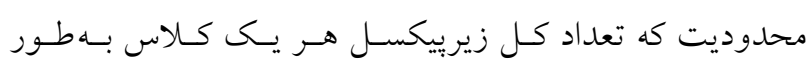

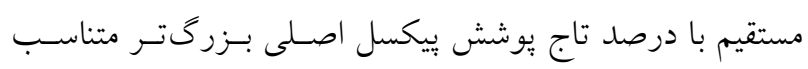

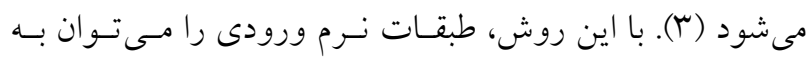

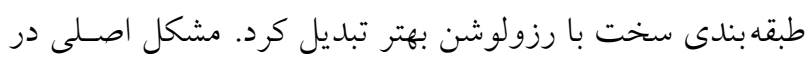

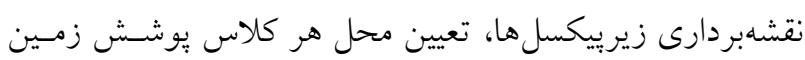

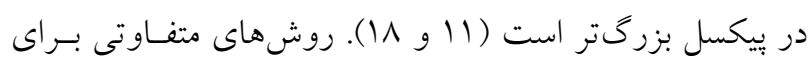

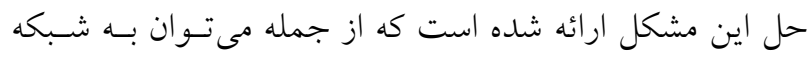

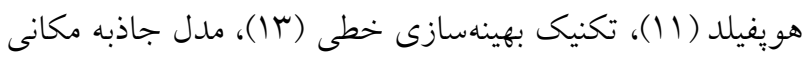




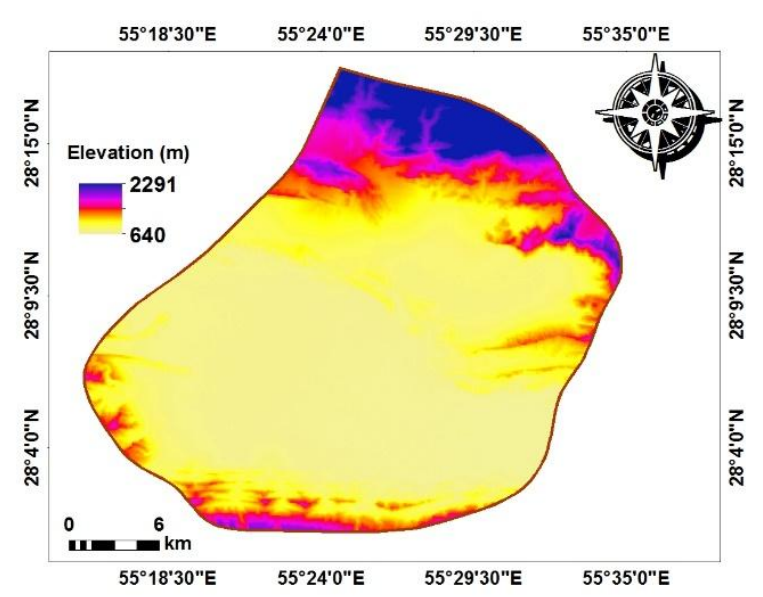

شكل ا. موقعيت جغرافيايى منطقه (مدل رقومى ارتفاع با قدرت تفكيك مكانى ه9 متر )

قرار مى گيرد و در مدل همسايكى جهار كانه، فقط بيكسلهـا در

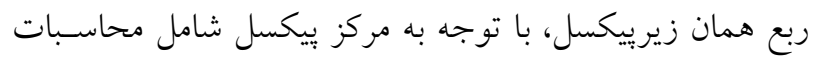
مىشود.

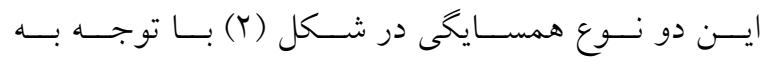

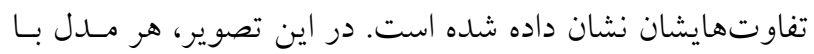
سه مقياس مختلف نشان داده شده است. فـاكتور مقيـاس تعـداد

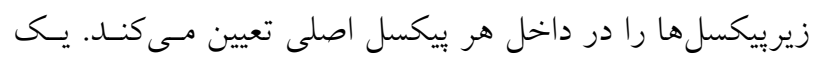

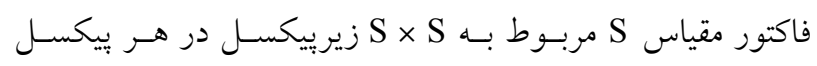
مركزى است.

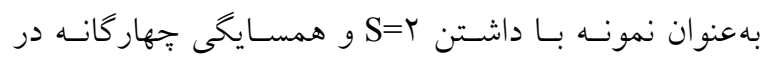

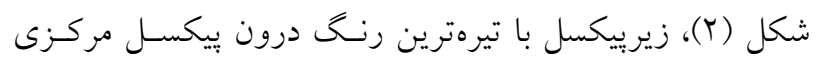

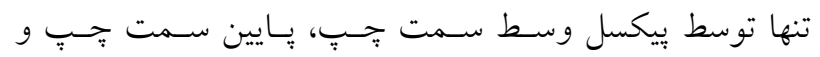

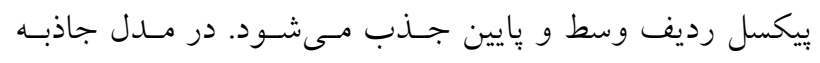

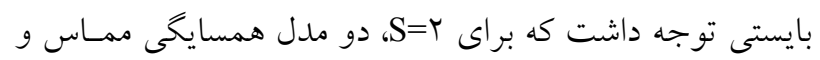

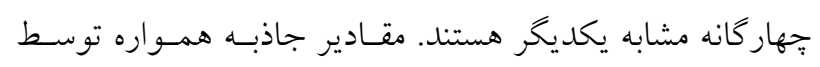

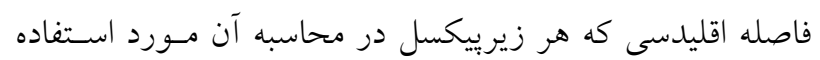

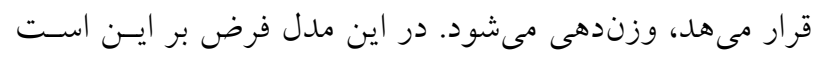

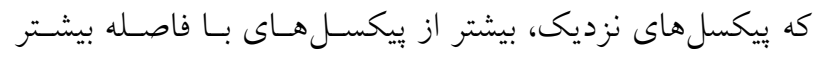

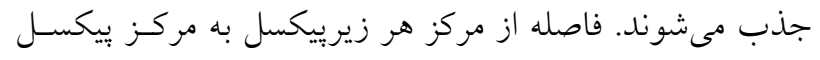
مورد نظر محاسبه مى شود و فرض بر اين است كه تمـام جاذبـهـ

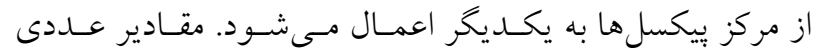

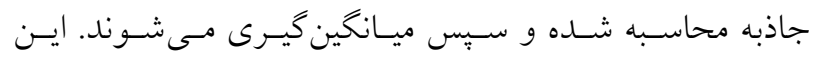

از توابع استان فارس در هQ درجه و ها دقيقه تا هQ درجه و بr

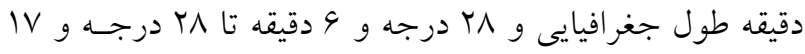

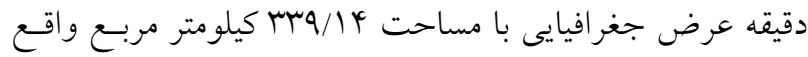

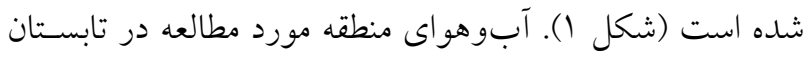

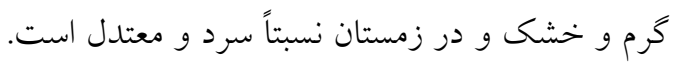

مدل جاذبه در زيرييكسل ها

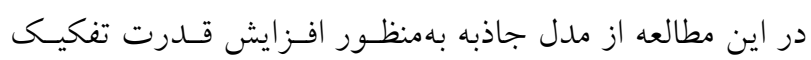

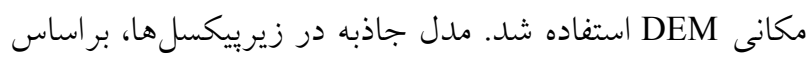

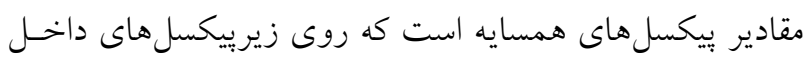

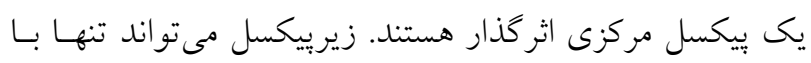

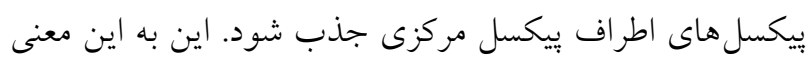

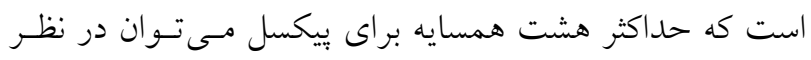

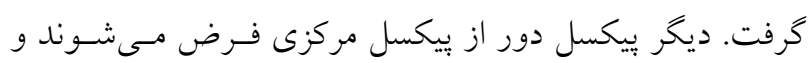

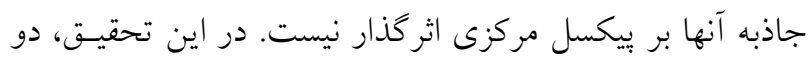

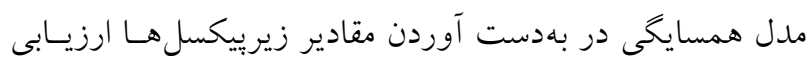

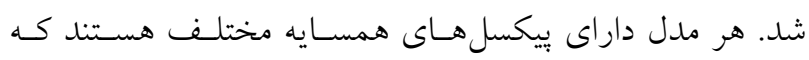

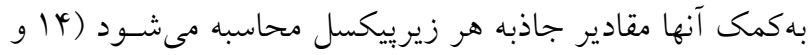

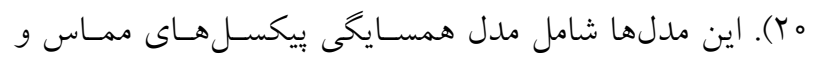

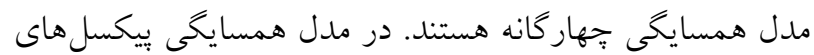
مماس، فقط بيكسل هايى كه از نظر فيزيكى مماس به زيرييكسل

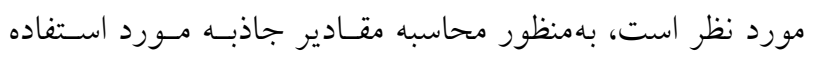




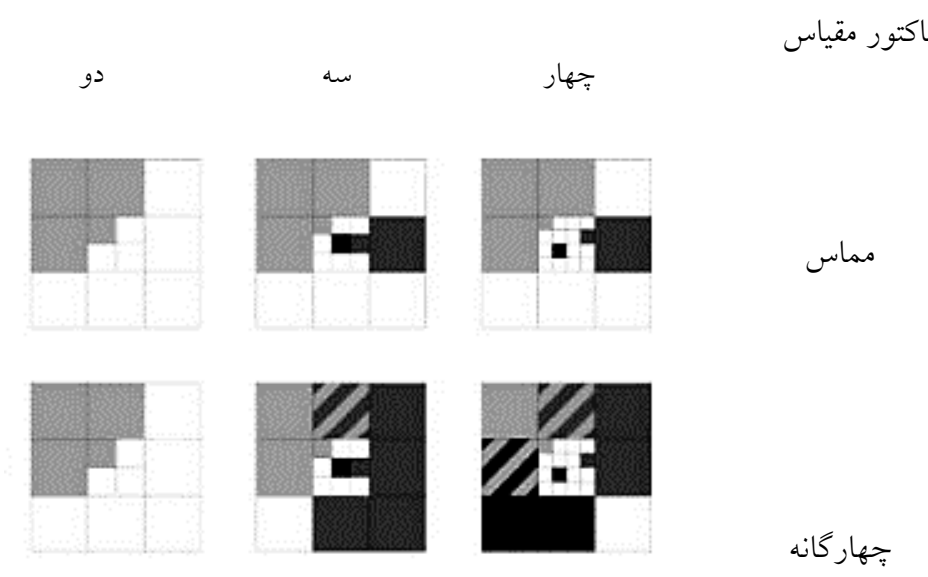

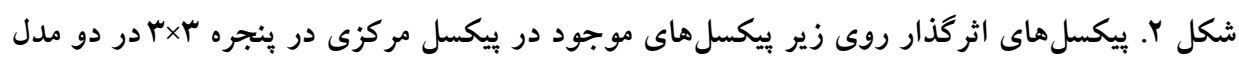

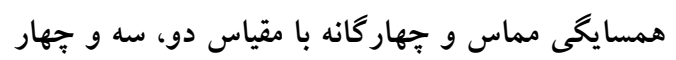

در اين روابط، N المدل همسايكى مماس و Nr مدل مدل همسايكى

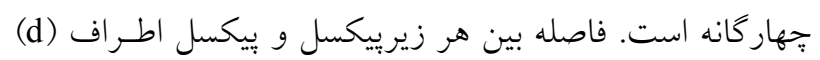

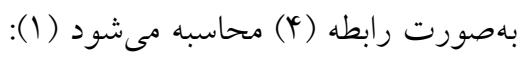
$d\left(p_{a ; b} \cdot P_{i ; j}\right)=\sqrt{[a+o / \Delta-S(i+o / \Delta)]^{r}+[b+o / \Delta-S(j+o / \Delta)]^{r}}$

در اين مطالعه براى افزايش قدرت تفكيك مكانى DEM از مدل

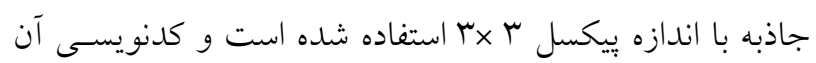

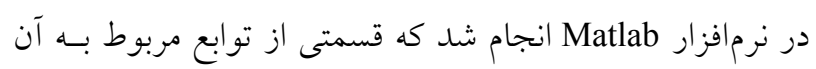

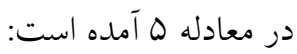

$\operatorname{Model}(\mathrm{S}, \mathrm{t}$, input) function $[$ result $]=$ Attraction result $=\operatorname{nan}(\mathrm{S}, \mathrm{S})$;

for $\mathrm{a}=0: \mathrm{S}-1$

for $b=0: S-1$

without class Values, Attraction [ Classes,

(S,t ,input, a, $\bar{b})$; normalization $]=$ neighborhood

result $(a+1, b+1)=$ class_without_normalization; end

ورودى اين معادله، ينجرههاى ب×rا، S: فاكتور مقياس، T: روش همسايكى، a و b موقعيت زيرييكسل ها است.

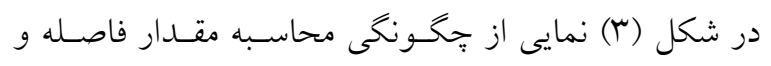

سيستم مختصات تعريف شده، نشان داده شده است (Yo (Y).

در روابط ذكر شده، فاكتور مقياس و نوع همسايخى مورد نظر سترن

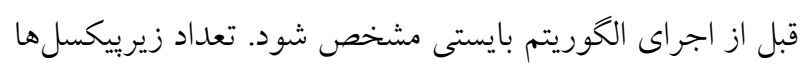

ميانخين گيرى به اين منظـور اسـت كـه ممكـن اسـت برخسى از

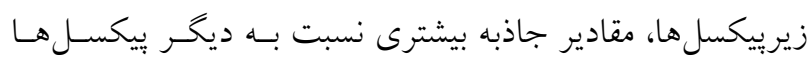

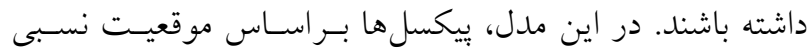

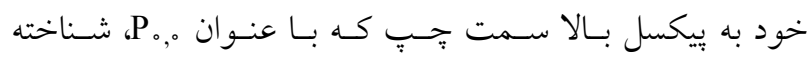

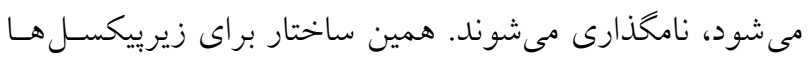

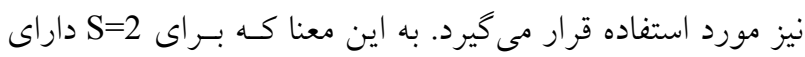

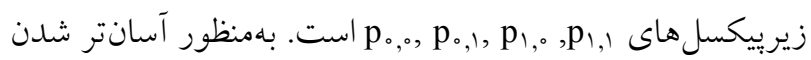

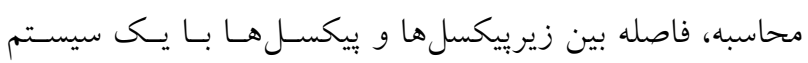

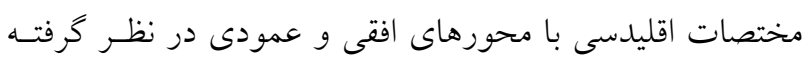

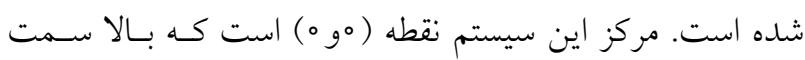

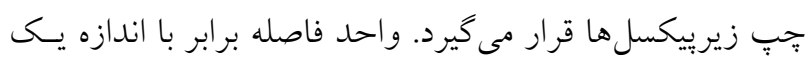

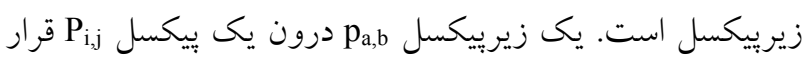
مى گيرد، هنخامى كه معادله ( (1) برقرار است (Yo (Y):

$p_{a ; b} \in P_{i ; j} \Leftrightarrow\left(\frac{a}{S}=i\right) \wedge\left(\frac{b}{S}=j\right)$

كه در آن: شماره سطر زيرييكسل، bماره ستون زيرييكسل

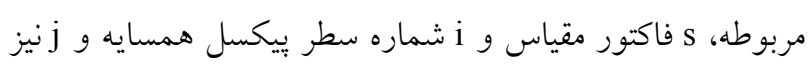
شماره ستون بيكسل همسايه است. همسايخى هاى تعريف شـائه

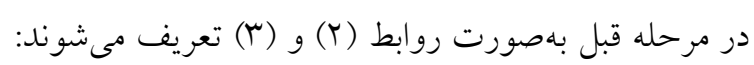
$\mathrm{N} \backslash\left[\mathrm{p}_{\mathrm{a} ; \mathrm{b}}\right]=\left\{\mathrm{P}_{\mathrm{i} ; \mathrm{j}} \mid \mathrm{d}\left(\mathrm{p}_{\mathrm{a} ; \mathrm{b}} \cdot \mathrm{P}_{\mathrm{i} ; \mathrm{j}}\right) \leq \frac{1}{\sqrt{\mathrm{r}}}(\mathrm{S}+1)\right\}$

$N r\left[p_{a ; b}\right]=\left\{P_{i ; j} \mid d\left(p_{a ; b} \cdot P_{i ; j}\right) \leq \frac{1}{\sqrt{r}}(r S-1)\right\}$ 


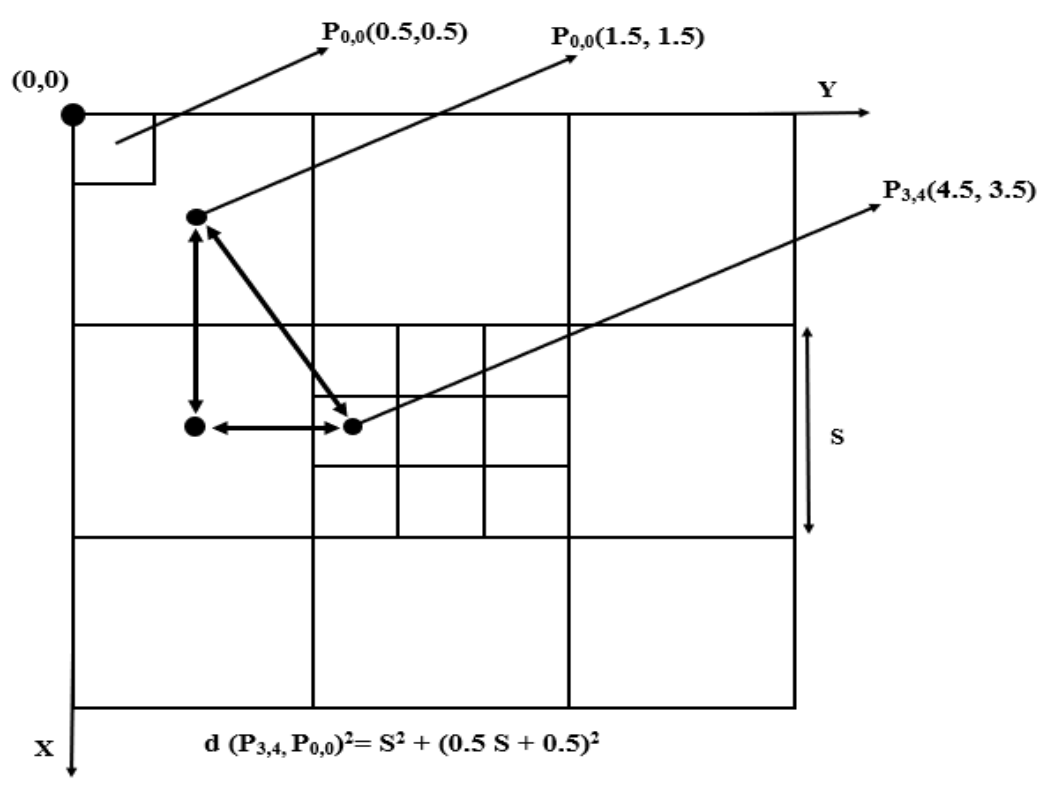

شكل r. نمايى از سيستم مختصات مورد استفاده بهمنظور محاسبه فاصله بين زيرييكسل ها و هر بيكسل اطراف از طريق محاسبه فاصله اقليدسى

كاس خـاص مـورد اسـتفاده قـرار گيـرد. زيربيكسـلهـايى بـا بيشترين مقدار جاذبه به كلاس مربوطه اختصاص مسىيابــ (ه). مراحل مختلف مدل جاذبه بـهـهنــور افـزايش قـدرت تفكيـك مكانى در مدل رقومى ارتفاع (DEM) در شـكل (4) نشـان داده شده است.

\section{بررسى اعتبار هريك از مدلها}

بهمنظور ارزيابى و تعيين بهترين مدل بهمنظور تخمين ارتفاع با

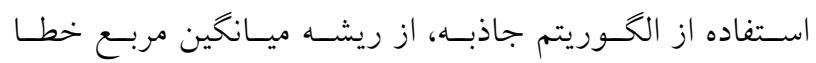
استفاده شد. به كمـك RMSE (RMSE) بيشبينى شده توسط مدل و مقدار واقعى تعيين مىشود (معادله

$$
\operatorname{RMSE}=\sqrt{\frac{1}{\mathrm{~N}} \sum_{\mathrm{i}=1}^{\mathrm{N}}\left\{\mathrm{Z}\left(\mathrm{x}_{\mathrm{i}}\right)-\hat{\mathrm{z}}\left(\mathrm{x}_{\mathrm{i}}\right)\right\}^{r}}
$$

در ايسن معادلـه، Z

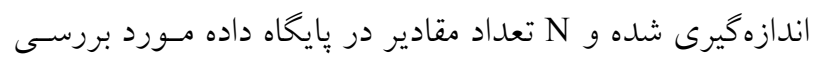
است. بررسى صحت تصـاوير بــا اسـتفاده از RMSE شـبيه بـهـ مطالعات تاتيم و همكاران (IV) است.
براى هر كلاس محاسبه شده و فقـط محهـود بـه اعـداد صـحيح مىشود. بقيه زيربيكسل ها نيز مورد استفاده قرار نمى گيرند. مقدار جاذبه (Attraction Value) خام براى زيرييكسل مa,b)

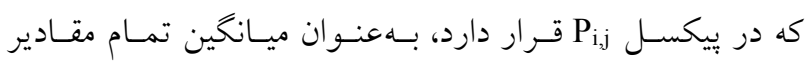
بيكسل هاى كلاس c براى بيكسل P در همسايكى زيربيكسل تقسيم بر فاصله بين بيكسل pa,b

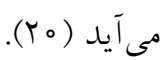

$\mathrm{p}_{\mathrm{a} ; \mathrm{b}}(\mathrm{c})=\operatorname{Avg}\left\{\frac{\mathrm{P}_{\mathrm{i} ; \mathrm{j}}(\mathrm{c})}{\mathrm{d}\left(\mathrm{p}_{\mathrm{a} ; \mathrm{b}} \cdot \mathrm{P}_{\mathrm{i} ; \mathrm{j}}\right)} \mid \mathrm{P}_{\mathrm{i} ; \mathrm{j}} \in \mathrm{N}_{\mathrm{t}}\left[\mathrm{p}_{\mathrm{a} ; \mathrm{b}}\right]\right\}$

بنابر اين با در نظر كرفتن همسايخى هاى مختلـف مقـادير جاذبـه براى تمامى زيرييكسل ها درون بيمسل مركزى محاسبه مىشود. اين مقادير جاذبه در حقيقت مقادير جاذبـه بـهازاى هـر كـلاس هستند. با اين فرض كه مقادير هر بيكسل روى ساير بيكسل هـا اثر گذار است، مقادير جاذبه مىتواند براى هر كلاس زيرييكسـل محاسـبه شـود. بــا ايسن حـال مقــادير جاذبـه زيرييكسـل بـراى بيكسل هاى مختلف قابل ميانحين گيرى است. يسس از مشـخص شدن قوانين جاذبه، مقادير خام جاذبه محاسـبه مسىشـوند. ايسن

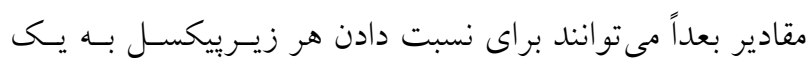




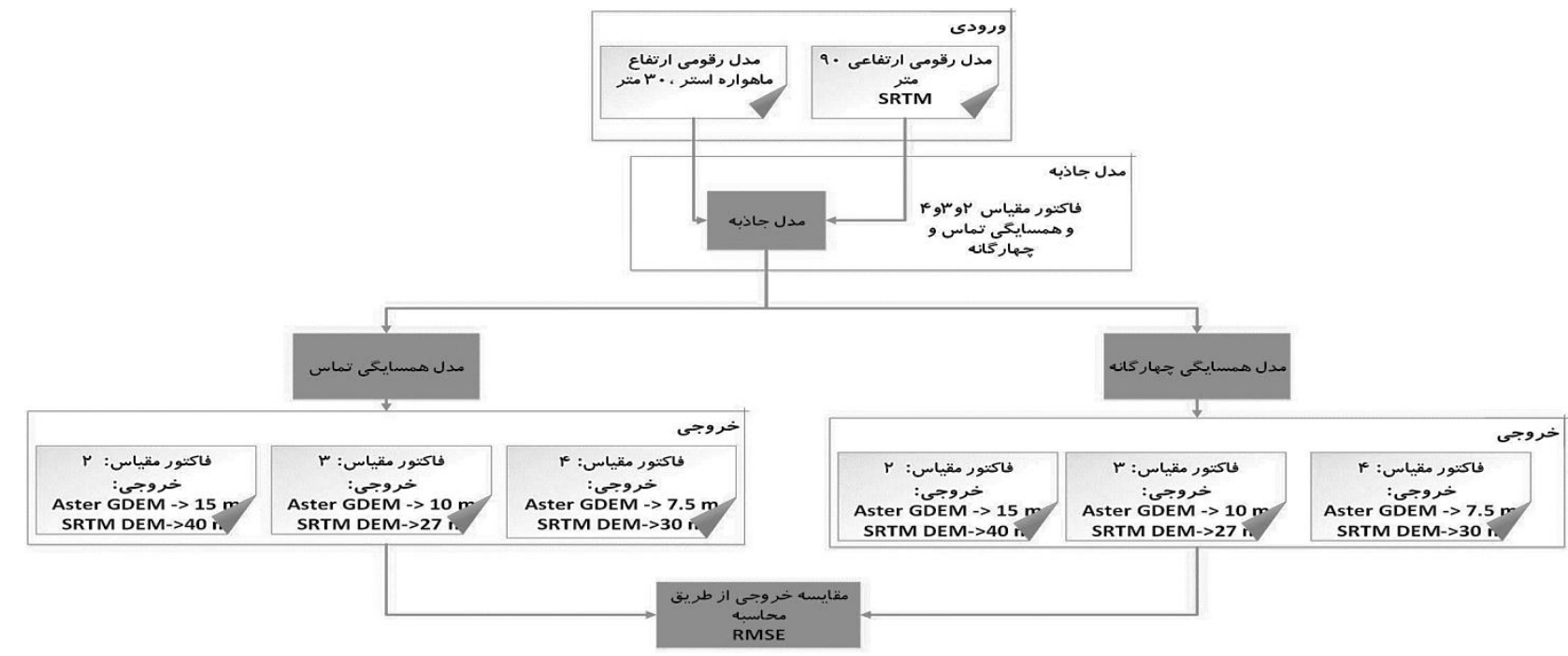

شكل †. مراحل مختلف اجراى فرايند افزايش قدرت تفكيك مكانى مدل رقومى ارتفاع با استفاده از الكوريتم جاذبه

رودخانه در رتبه خاص است.

$\mathrm{R}_{\mathrm{h}}=\mathrm{H} / \mathrm{L}$

در اين رابطه، H: كل رليف منطقـه و L: طـول حوضـه آبخيـز

$\mathrm{D}=\mathrm{L}_{\mathrm{u}} / \mathrm{A}$

[11]

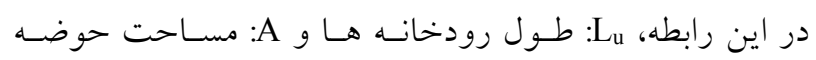
آبخيز است.

$\mathrm{F}_{\mathrm{S}}=\mathrm{N}_{\mathrm{u}} / \mathrm{A}$

در اين رابطه، A: مساحت حوضه آبخيز و N N تعـداد آبراهـه

است.

نتايج بهمنظور بررسى مدل جاذبه براى افزايش قدرت تفكيك مكسانى

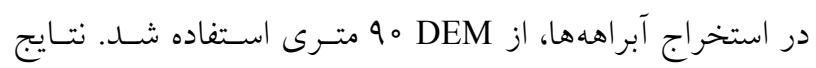

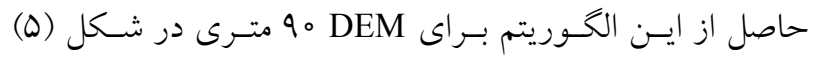

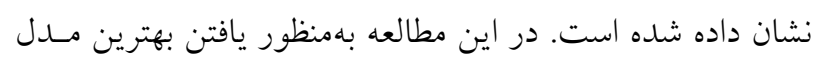

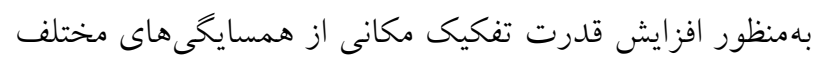

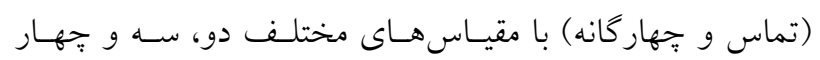

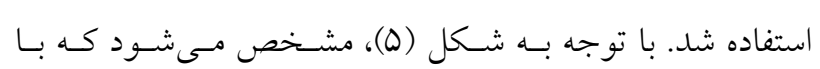

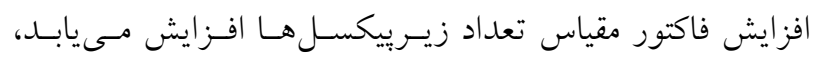

\section{مورفومترى آبراهههاى}

در اين مطالعه بهمنظور بررسى مورفومترى آبراهههـاى منطقـهـ

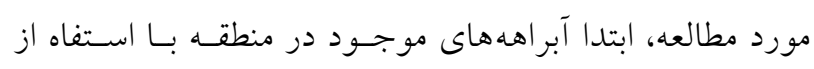

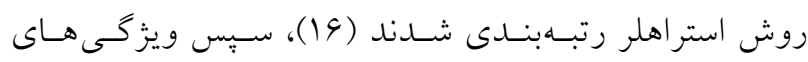
مورفومترى براى رتبه هاى مختلف مورد بررسى و مطالعه قرار

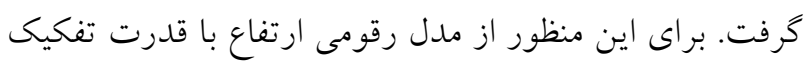

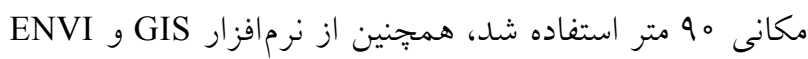

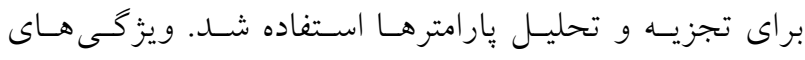

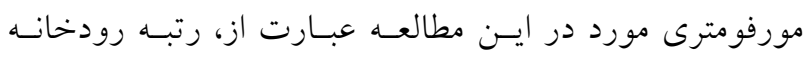

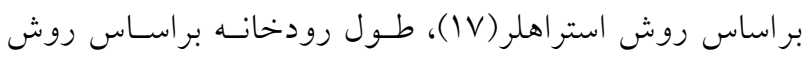

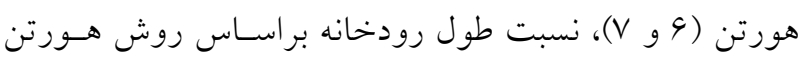

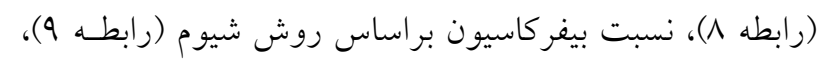

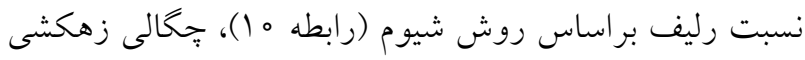

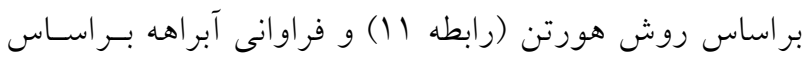

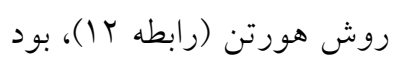

$\mathrm{R}_{\mathrm{L}}=\mathrm{L}_{\mathrm{u}} / \mathrm{L}_{(\mathrm{u}-1)}$

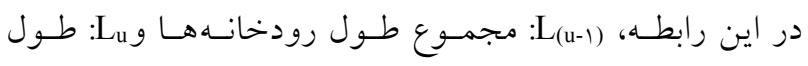
رودخانه است.

$\mathrm{R}_{\mathrm{b}}=\mathrm{N}_{\mathrm{u}} / \mathrm{N}_{(\mathrm{u}+1)}$

در اين رابطه، 


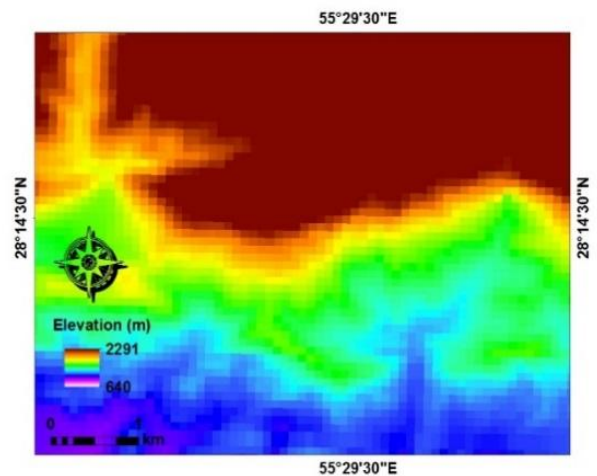

$\operatorname{DEM} 9$ 。

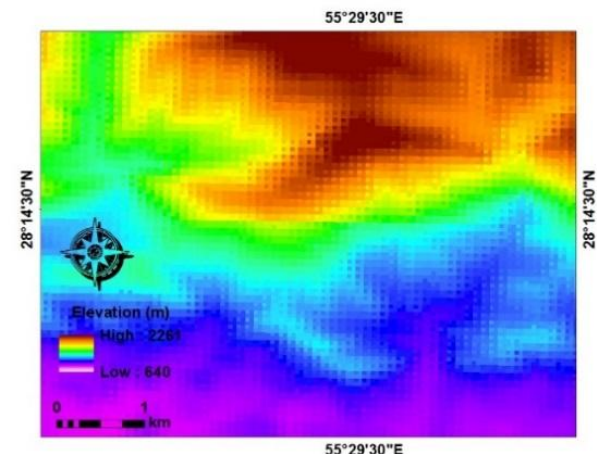

$S=r, T=r$

55 $29^{\circ} 30^{\circ \mathrm{E}}$

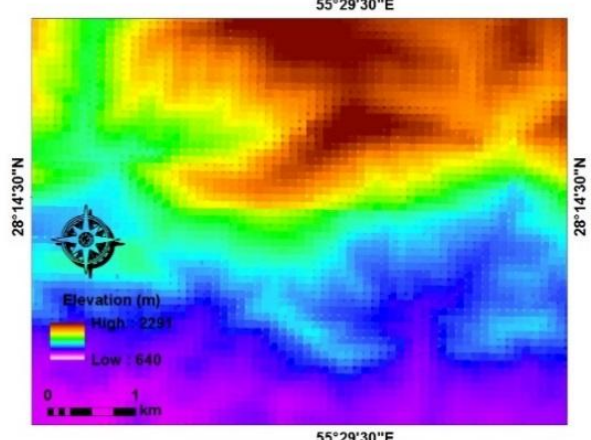

$S=r, T=r$

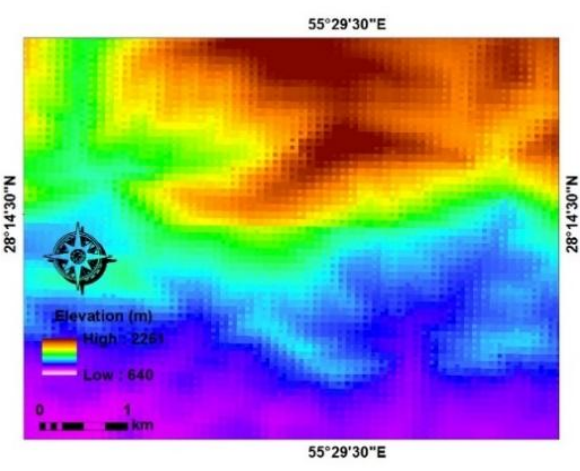

$S=r, T=1$

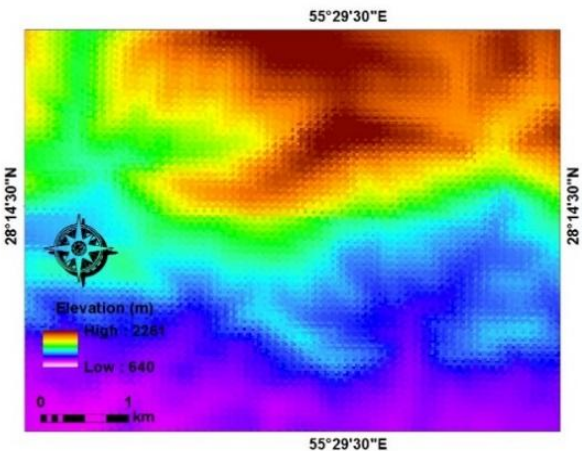

$S=r, T=1$

55⒉ $29^{\prime} 30^{\prime E}$

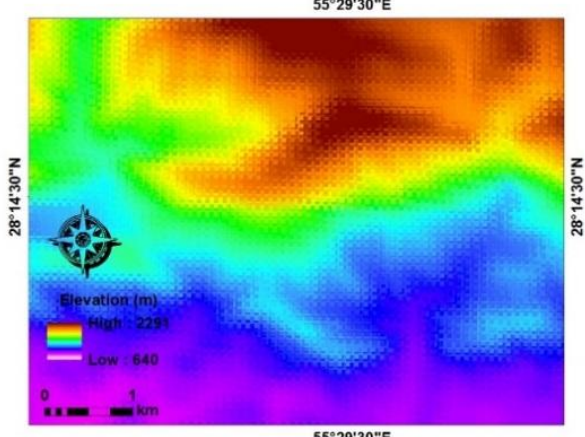

$S=r, T=1$

$55^{\circ} 29^{\prime} 30^{\prime \prime E}$

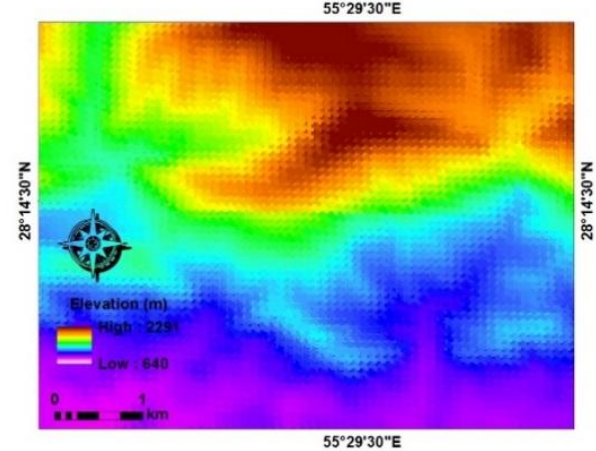

$S=r, T=r$

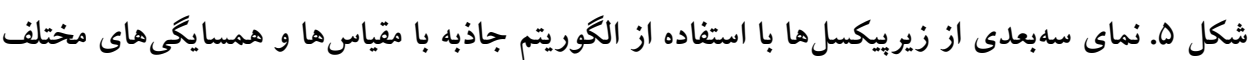

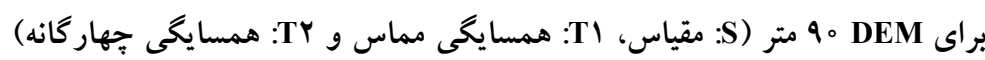




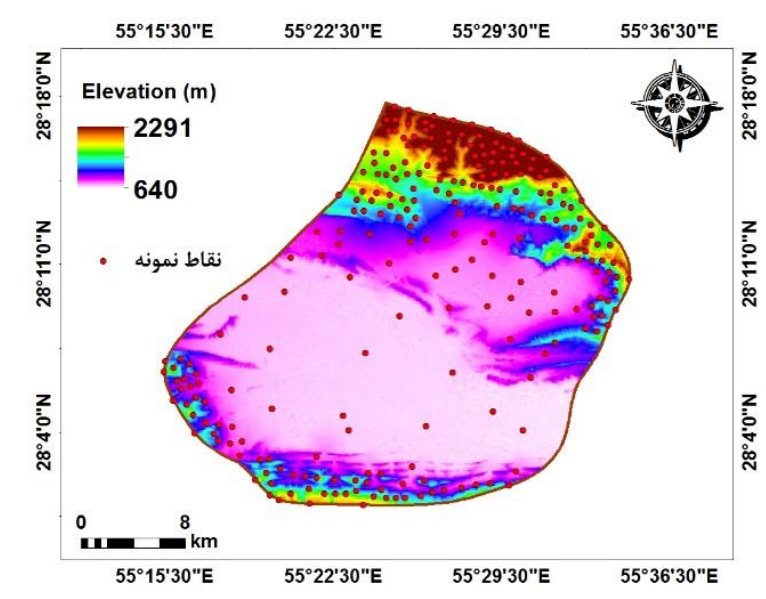

شكل 9. موقعيت و بر اكندگى نقاط كنترل زمينى در منطقه

جدول ا. مقادير RMSE براى هر يك از روشها با استفاده از DEM DQ Dت متر

\begin{tabular}{|c|c|c|c|c|c|c|c|}
\hline D DEM مترى & $S=r, T=r$ & $S=r, T=1$ & $S=r, T=r$ & $S=r, T=1$ & $S=r, T=r$ & $S=r, T=1$ & روش \\
\hline$N / \circ \mathrm{V}$ & N/^q & K & $9 / 11$ & V/VG & $1 / \circ 9$ & $1 / \circ 9$ & مقادير RMSE \\
\hline
\end{tabular}

اين مقادير نمايش داده شده است. مطالعات نشان مسىدهـد كـه استفاده از روشهاى زيربيكسل موجب افزايش قدرت تفكيـك لفيس زمينى مدلهاى رقومى زمين شده و ايسن امـر موجـبـ افـزايش

$$
\text { دقت اين مدلها مىشود. }
$$

با توجه به مقادير ارتفاع براى هر يك از نقـاط (شـكل 9) و

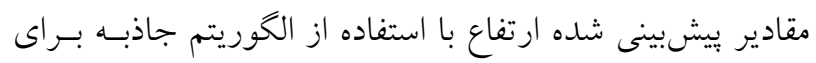
هر يك از زيربيكسل هــا، مقـادير RMSE در جــدول (1) نشـان داده شده است. با توجه به مقادير RMSE مشخص مىشود كـه بهترين مدل بهمنظور افزايش قدرت تفكيك مكانى، مدل س ب براى DEM متر اسـت. در نتيجـهـ از ايسن مــدل بـراى

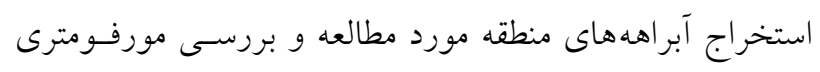
آنها استفاده شد. بعد از مشخص شدن بهترين مدل براى استخراج آبراهههـا، در محيط GIS، آبراهههاى منطقه مورد مطالعه استخراج شـدند (شكل V)، هم:حنين براى مقايسه بهتر مــل جاذبـه و DEM، از

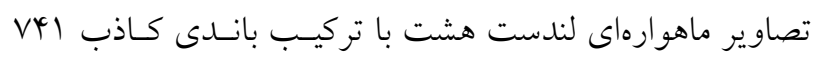

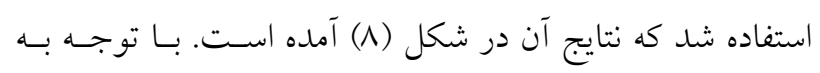

بهوطورى كه اطلاعات در زيرييكسل ها نسـبت بـه بيكسـل اوليـه بيشتر شده و تغييرات ارتفاعى را بهتر نشان مىدهد. بنـابراين از

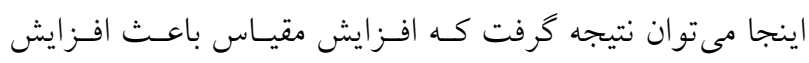
قدرت تفكيك مكانى DEM مىشود. همانطوركه در شكل نشان داده شده در مقياس هاى بزرگتر (SY) تعداد بيكسل ها افز ايش

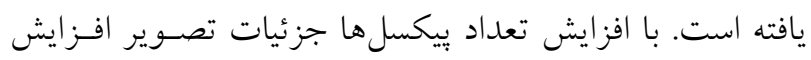

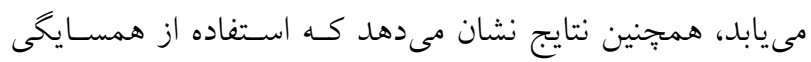
مماس (TI) نسبت به همسايخى جهار گانه (TY) باعث افـزايش تعداد زيرييكسل ها و افزايش قدرت تفكيك مكانى مىشود. بـهمنظـور مقايسـه و تعيسين بهتـرين مقيـاس و همسـايخى، ارتفاعات تعيين شده براى هريك از زيرييكسلها، توسـط مــل جاذبه با نقاط زمينى مقايسه شد. تعداد كل نقـاط كنتـرل زمينى نقطه بود كه بهصورت تصادفى در منطقه ير اكنده شــدهانـد. اين نقاط كنترل زمينى از طريق عمليات نتشهبــردارى اسـتخراج شدهاند. در شكل (9) موقعيت اين نقاط و بر اكندكى مربوطه بـهـ آنها نمايش داده شـده اسـت. مقــار RMSE بـراى هـر DEM،

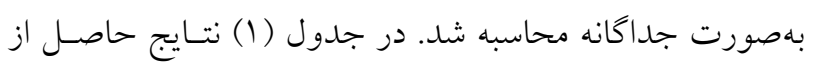



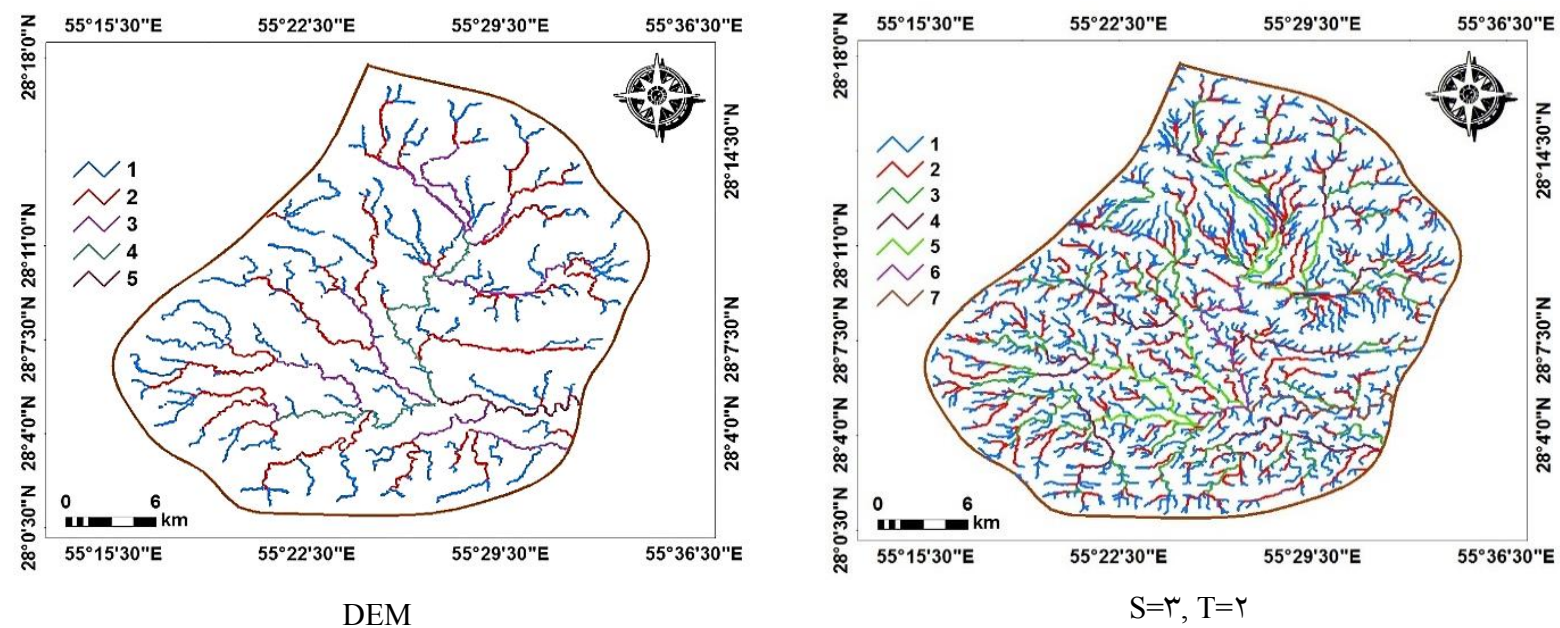

شكل V. آبراهdهاى مستخرج از مدل جاذبه و Q DEM متر در منطقه مورد مطالعه

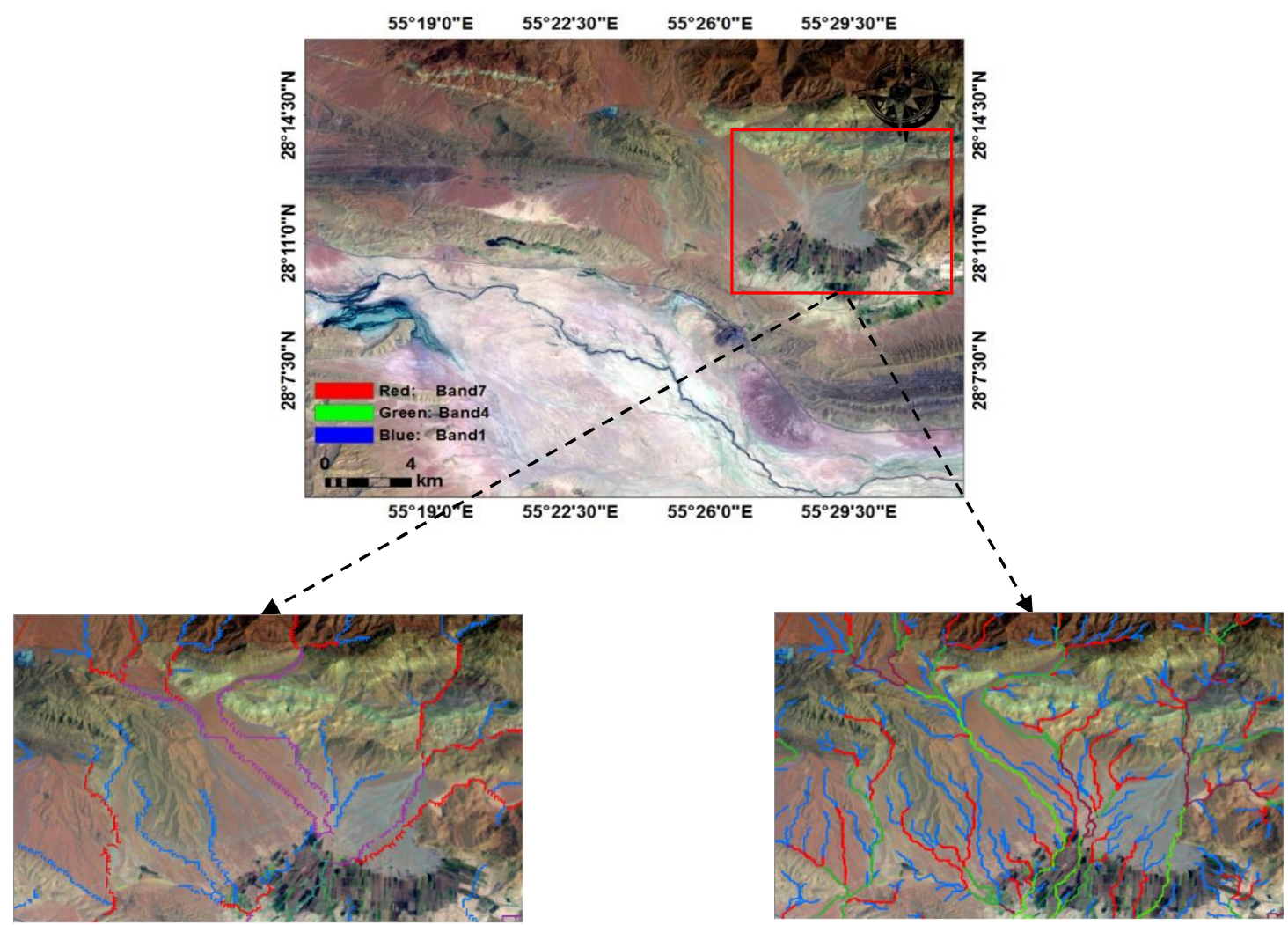

شكل ^ـ موقعيت آبراههها بر روى تصاوير ماهوارهاى لندست هشت (Y०10)

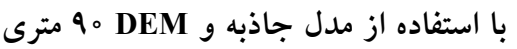

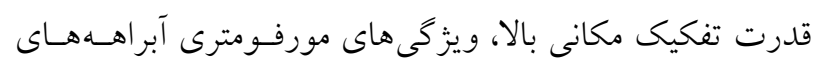

منطقـهـ مشـخص شـــ تجزيـهـ و تحليـل مورفـومترى مـا را در

شناخت فرايندهاى زئومورفولوزى و هيدرولوزى آكاه مى مسـازد.
شكل مشخص مى شود كه مدل جاذبه داراى دقت بيشترى براى استخراج آبراههها است.

بعد از مشخص كـردن بهتـرين مـدل بـراى تهيـه DEM بـا 
جدول r. رتبه و طول آبر اهه منطقه مورد مطالعه

\begin{tabular}{|c|c|c|c|c|c|c|c|c|}
\hline \multicolumn{7}{|c|}{ تعداد آبراهلهها } & \multirow{2}{*}{ رتبه رودخانه } & \multirow{2}{*}{ DEM } \\
\hline V & 4 & 0 & $r$ & r & r & 1 & & \\
\hline$\circ$ & $\circ$ & 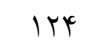 & MTS & VA & 19Y9 & rory & 0 & D DEM مترى DEM \\
\hline gry & 191 & מצחז & rovo & WVq4 & lYVG。 & miky. & v & $S=r, T=r$ \\
\hline \multicolumn{7}{|c|}{ طول آبراهه (كيلومتر) } & \multirow{2}{*}{ رتبه رودخانه } & \multirow{2}{*}{ DEM } \\
\hline V & 9 & 0 & 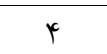 & r & r & 1 & & \\
\hline 。 & 。 & $10 / T V$ & rV/ro & $\Lambda r / 9 G$ & $|V| / 90$ & MII/VA & & •9EM مترى D D \\
\hline $19 / 79$ & TE/VV & $V 0 / 9 \wedge$ & $10 \wedge / \mu r$ & $r r V / q 1$ & YYV/VA & $909 / V 9$ & & $S=r, T=r$ \\
\hline
\end{tabular}

\begin{tabular}{|c|c|c|c|c|c|c|c|}
\hline \multicolumn{6}{|c|}{ نسبت طول آبراهـ } & \multirow{2}{*}{ رتبه رودخانه } & \multirow{2}{*}{ DEM } \\
\hline V به 9 & 9 به 0 & ه به & r به r & r r r & Tبه 1 & & \\
\hline$\circ$ & $\circ$ & $\circ / \mathcal{F}_{0}$ & $0 / y^{4}$ & $\circ / \uparrow \wedge$ & $\circ / \Delta \Delta$ & 0 & ه D DEM \\
\hline$\circ / \mathrm{VI}$ & $\circ / \mu V$ &.$/ 90$ & $0 / 4 \Delta$ & $\circ / \Delta \mu$ & $0 / 49$ & V & $S=r, T=r$ \\
\hline
\end{tabular}

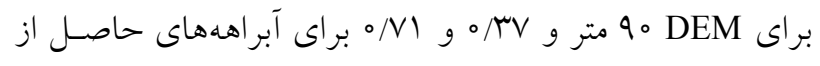
مدل جاذبه است. ضريب بيفركاسيون نشاندهنده نسبت بين تعداد آبراهلهــاى يك رتبه به رتبه بـالاتر از آن اسـت (سا). ضـريب بيفركاسيون

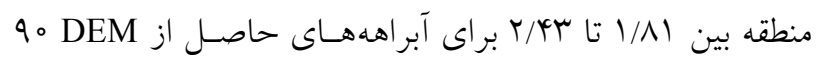

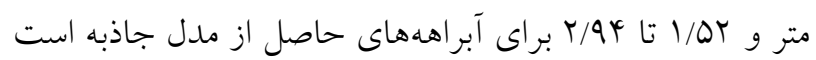

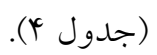
هم:جنين فاكتورهايى مانند جخالى زهكشى و فراوانى آبراهـه محاسبه شد كه در جدول (ه) نشان داده شده است. بـا توجـه بـهـ

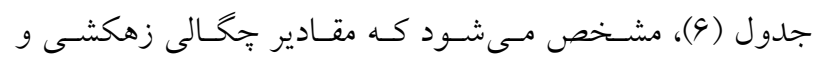

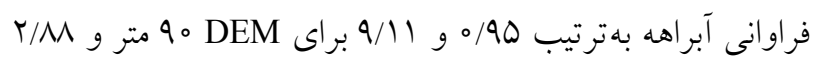

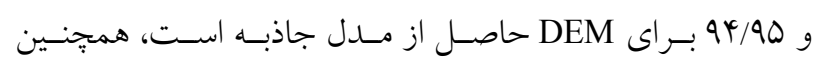
بهمنظور بررسى ويزز گیى هاى مورفومترى منطقـه مـورد مطالعـه، از نسبت رليف منطقه استفاده شد كه در واقع تفاوت بـين حسـداقل و حداكثر ارتفاع به طول حوضه آبخيز در منطقه اسـت (9). نتسايج مربوط به بِتى و بلندىهاى منطقه در جدول (9) آمده است.
بهمنظور تجزيسه و تحليـل مورفـومترى، از ويزگى هـاى خطى آبر اهلها و يُستى و بلندىهاى منطقه مورد مطالعه استفاده شــد.

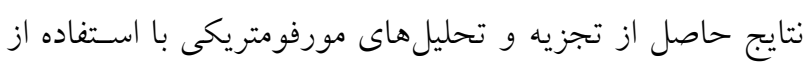

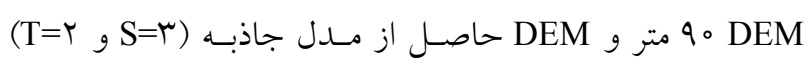
نشان داد كه تعداد رودخانههاى موجود در منطقه مـورد مطالعـه

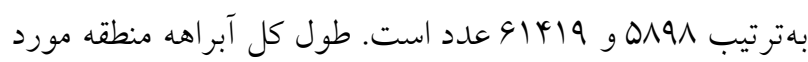

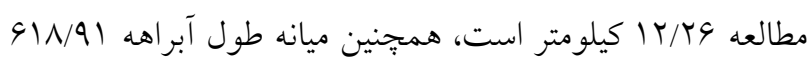

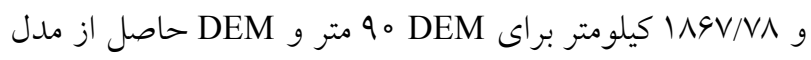
جاذبه است. جدول (Y) نشاندهنده طول آبراهه و تعداد آبراهـه براى هر يك از رتبه هاى آبراهههاى حاصل از DEM م متر و DEM حاصل از مدل جاذبه است.

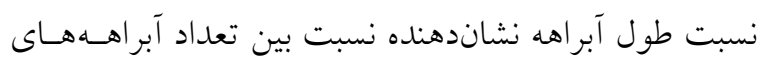
يك رتبه به رتبه يايينتر از آن است. نسبت طـول آبراهـه بـراى

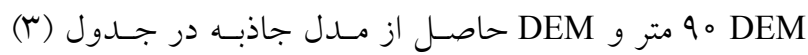
نشان داده شده است. با توجه به جدول (r) مشـخص مسى شـود كه حداقل و حداكثر نسبت طول آبراهه، بهترتيب صـفر و هه/ه 


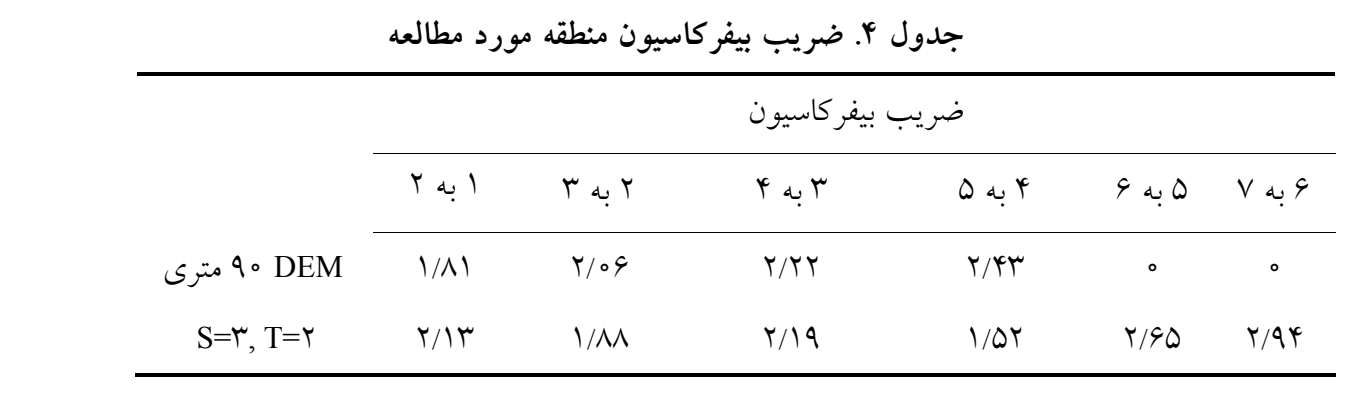

جدول ه. مقادير مربوط به جگحالى زهكشى و فراوانى آبراهه در منطقه مورد مطالعه

\begin{tabular}{|c|c|c|}
\hline & جُشالى زهكشى & فروانى آبراهد \\
\hline • DEM مترى & $\circ / 90$ & $9 / 11$ \\
\hline$S=r, T=r$ & $r / \Lambda \Lambda$ & $94 / 90$ \\
\hline
\end{tabular}

جدول 8. نسبت رليف منطقه مورد مطالعه

\begin{tabular}{|c|c|c|c|}
\hline & حداكثر ارتفاع بر حسب متر & حداقل ارتفاع بر حسب متر & نسبت رليف \\
\hline ه9 D مترى & rYqI & 940 & 91 \\
\hline$S=r, T=r$ & rYqI & s4o & $9 \wedge$ \\
\hline
\end{tabular}

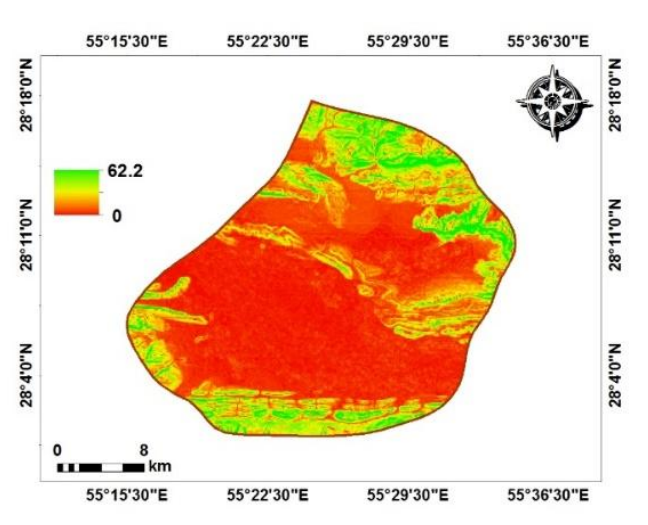

$\operatorname{DEM} 9 \circ$

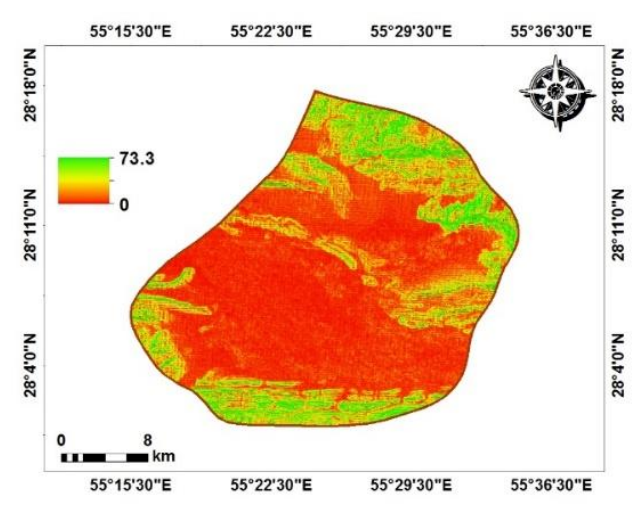

$S=r, T=r$

شكل 9. نقشه شيب منطقه مورد مطالعه

مورد مطالعه، ك/ 9 درجسه بــراى

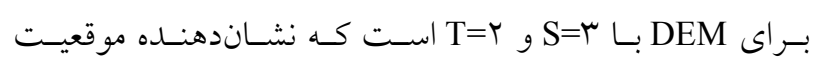
متوسط منطقه از نظر فرسايش و سيلابى است.

با توجه به نتايج بالا مشخص مىشـود كـهـ اسـتفاده از مــل جادبه بهمنظور استخراج آبراهـههـا و بررسسى مورفـومترى آنهـا داراى دقت بالايى است. مدل جاذبه براى محاسبه زيربيكسل هــا
منطقه مورد مطالعه از نظر شيب نيز مورد بررسسى و مطالعـه

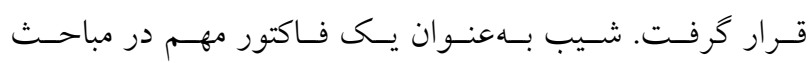

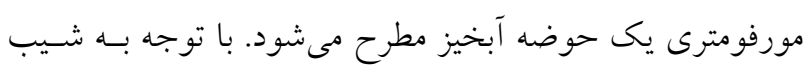
مى توان ميزان سيلابى بودن و فرسايش را يـيشبينسى كـرد و بـا ايجاد يك راهكار، مديريت حوضه آبخيز را بهخوبى انجـام داد. با توجه به شكل (9) مشخص مى شود كه حداكثر شـيب منطقـه 
وضعيت يُتى و بلندى و نقشه زئومورفولـوزى منطقـه اسـتفاده

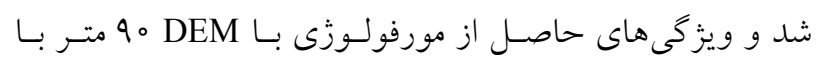
ويزگگىهاى مورفولوزى DEM حاصل از مدل زيرييكسل جاذبـه با قدرت تفكيك مكانى بهتر، مقايسه شد. در اين تحقيق قـدرت

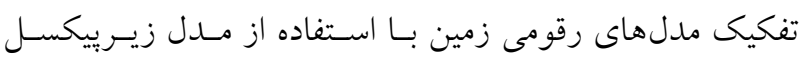
جاذبه افزايش بيدا كرد. الخوريتم مربوطه هم بهصورت بصى بصرى، هم بهصورت آمارى بررسى و شاخص RMSE براى آن محاسبه

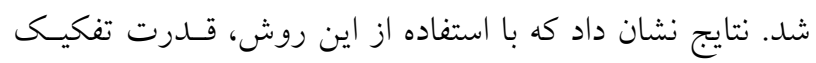
مدل رقومى زمين با صرف هزينه و زمان كمتر بهبود بيــا مسىكند. در برخى موارد صحت مدل خروجى هم با استفاده از ايسن

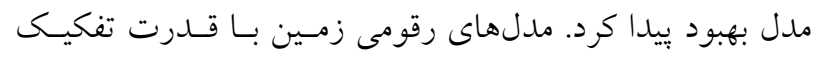
بهتر مىتواند براى استخراج عوارض و اطلاعات بيشتر از زمسين استفاده شـود. نتـايج حاصـل از بررسـى خطى حوضـه آبخيـز نشاندهنده زمان تمركز كمتر و در نتيجه سـيلابى بـودن منطقـه مورد مطالعه است، همجينين براساس مطالعات يستى و بلندىهـا مشخص شد كـه وجـود ارتفاعـات زيـاد در منطقـه، منجــر بــه سيلابى شدن منطقه شده است.
روى تصاوير ماهوارهاى توسـط ملكىى و همكـاران ( (1) اعمـال شده است و طراحى الخــوريتم مربوطـهـ بـا اسـتفاده از تصـاوير

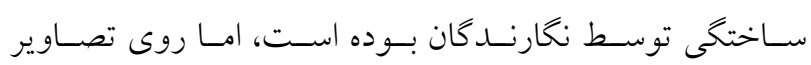
ماهوارهاى واقعى نيز اين الخوريتمها اجرا شدهاند و نتـايج قابـل قبولى را ارائه كردهاند. الكوريتم هم از نظر بصرى و هم از نظـر آمارى مورد بررسى قرار كرفته است و شاخصىهاى مـورد نظـر بهمنظور نشان دادن صحت انجام الخوريتم روى آنها اجـرا شــده است. تصاوير ماهوارهاى خروجى، نشـاندهنــده افـزايش دقـت زمانى در مقايسه با تصاوير ورودى هستند.

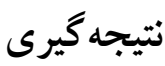

بررسى مورفـومترى يـى حوضـهـ آبخيـز بـهمنظسور بررسىى و مديريت حوضه آبخيسز، جلـو گيرى از سـيلاب و فرسـايش و ..

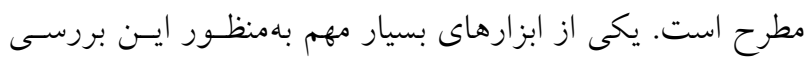

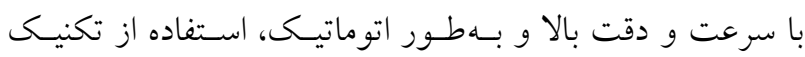
سـنشش از راه دور و GIS اسـت. بــهنظـور تجزيسه و تحليـل آبر اهه هاى منطقه مورد مطالعه از ويزز هى هاى خطى آبراهـهــا،

\section{منابع مورد استفاده}

ا. ملكى، ص. ف. خرمالى وع. كريمى. سوبا. معرفى الكوريتمهاى مختلف جريان براى تهيه نقشـه شـاخص خيسى و كـربن آلى

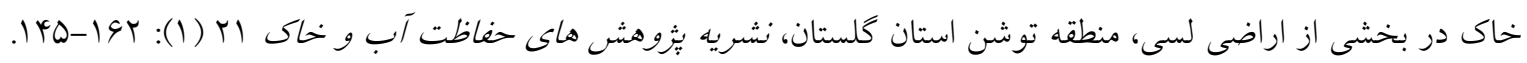

2. Ardila, J. P., V. A. Tolpekin, W. Bijker and A. Stein. 2011. Markov-random-field-based super-resolution mapping for identification of urban trees in VHR images. Journal of Photogram and Remote Sensing 66: 762-775.

3. Atkinson, P. M. 2005. Sub-pixel target mapping from soft-classified, remotely sensed imagery Photogram. Engineering Remote Sensing 71(7): 839-846.

4. Boucher, P. C., C. C. Kyriakidis and D. T. Ratcliff. 2008. Geostatistical solutions for super resolution land cover mapping, IEEE Trans. Geoscience Remote Sensing 46(1): 272-283.

5. Grabs, T., J. Seibert, K. Bishop and H. Laudon. 2009. Modeling spatial patterns of saturated areas: A comparison of the topographic wetness index and a dynamic distributed model. Journal of Hydrology 1(373):15-23.

6. Horton, R. E. 1932. Drainage basin characteristics. Transactions American Geophysical Union 13: 350-361.

7. Horton, R. E. 1945. Erosional development of streams and their drainage basins: hydro physical approach to quantitative morphology, Geological Society of America Bulletin 56: 275-370.

8. Magesh, N. S., N. Chandrasekar and J. P. Soundranayagam. 2011. Morphometric evaluation of Papanasam and Manimuthar watersheds, parts of Western Ghats, Tirunelveli district, Tamil Nadu, Iran: a GIS approach. Environment and Earth Science 64(2): 373-381

9. Melelli, L., L. Liucci, F. Vergari, S. Ciccacci and M. D. Monte. 2014. Fluvial drainage networks: the fractal approach as an improvement of quantitative geomorphic analyses. Geophysical Research 16: 1245-1253.

10. Mertens, K. C., B. D. Baets, L. P. C. Verbeke and R. D. Wulf. 2003. A sub-pixel mapping algorithm based on subpixel/pixel spatial attraction models. International Journal of Remote Sensing 27(15): 3293-3310.

11. Muad, A. M and G. M. Foody. 2012. Super-resolution mapping of lakes from imagery with a coarse spatial and fine 
temporal resolution. Journal of Applied Earth Observation Geo information (12)1: 79-91.

12. Parveen, R. Kumar, U and Kumar, S. V. 2012. Geomorphometric Characterization of Upper South Koel Basin, Jharkhand: A Remote Sensing \& GIS Approach. Journal of Water Resource and Protection. 4: 1042-1050.

13. Schumms, S. A. 1956. Evolution of drainage systems and slopes in Badlands at Perth Amboy, New Jersey. Bulletin of the Geological Society of America 67: 597-646.

14. Sorensen, R., U. Zinko and J. Seibert. 2005. On the calculation of the topographic wetness index: evaluation of different methods based on field observation. Hydrology and Earth System Sciences 10: 1-10.

15. Starr, G. C., R. Lal, R. Malone, D. Hothem, L. Owens and J. Kimble. 2000. Modeling soil carbon transported by water erosion processes. Land Degradation and Development 11: 83-91.

16. Strahler, A. N. 1964. Quantitative geomorphology of watersheds and channel networks, In: V. T. Chow (Ed.,) Handbook of Applied Hydrology, McGraw Hill Book Company. New York.

17. Tatem, A. T., H. G. Lewis and P. M. Atkinson. 2001. Super resolution target identification from remotely sensed images using a Hopfield neural network, IEEE Trans. Geoscience Remote Sensing (39)4: 781-796.

18. Verhoeye, R. D. and A. D. Wulf. 2002. Land cover mapping at sub-pixel scales using linear optimization techniques, Remote Sensing Environment 79(1): 96-104.

19. Wang, L. G., Q. M. Wang and D. F. Liu. 2011. Sub-pixel mapping based on sub-pixel to subpixel spatial attraction model, In: Proceedings of the 2011 IEEE International Geoscience and Remote Sensing Symposium, IGARSS, PP: 593-596.

20. Xu, X., Y. Zhong and L. Zhang. 2014. A sub-pixel mapping method based on an attraction model for multiple shifted remotely sensed images. Neuro-Computing 134: 79-91. 


\title{
Morphometric Assessment, Modeling and Waterway Extract from DEM using Sub-pixel Attraction Model
}

\author{
M. Mokarram ${ }^{1}$, A. R. Zarei ${ }^{2}$ and M. J. Amiri ${ }^{*}$
}

(Received: August 1-2017 ; Accepted: October 2-2017)

\begin{abstract}
The aim of this study was to evaluate the effect of increasing DEM spatial resolution on the assessment of the morphometric characteristics of waterways, as well as analysis and modeling of it by using RS and GIS techniques. In this study, which was carried out in the south of Darab city DEM $90 \mathrm{~m}$ (as one of the most usable data in waterway modeling), increase spatial resolution of DEM attraction algorithm in neighboring pixels with two models including: touching and quadrant neighboring models to estimate the value of sub-pixels. After manufacturing output images for sub pixels in 2, 3 and 4 scales with different neighborhoods, the best scale with the most appropriate type of neighborhood was determined using ground control points (270 points); then, the values of RMSE were calculated for them. The results showed that with using the Attraction model, the accuracy of the output of images was improved and the spatial resolution of them was increased. Among scales with different neighborhoods, 3 scales and quadrant neighboring model exhibited the most accuracy by the lowest value of RMSE for the DEM 90 meter. Evaluation of waterways morphometric features showed that DEM extracted from attraction algorithm had more ability and accuracy in waterways extraction, Extraction of morphometric complications, and information in the study area.
\end{abstract}

Keywords: Waterway morphometric, Waterway modeling, GIS, Attraction algorithm, Sub-pixel, DEM

1. Department of Range and Watershed Management, College of Agriculture and Natural Resources of Darab, Shiraz University, Iran.

2. Department of Rang and Watershed Management (Nature Engineering), Faculty of Agricultural Science, Fasa University, Fasa, Iran.

3. Department of Water Engineering, Faculty of Agricultural, Fasa University, Fasa, Iran.

*: Corresponding Author, Email: mj_amiri@fasau.ac.ir 